\title{
Rapid effect of one-day Isoprinosine intake on cytokine production in patients with chronic hepatitis B and healthy probands
}

\author{
Deian Jelev', Lyudmila Mateva', Dora Popova², \\ Zahariy Krastev'.
}

1. Clinic of Gastroenterology, University Hospital St "Ivan Rilski", Sofia;

2. Department of Clinical Immunology, Military Medical Academy, Sofia

\begin{abstract}
Isoprinosine is a drug with immunomodulatory and antiviral properties. It increases IFN- gamma, IL2, IL-10, and TNF-alpha serum levels at 7th to 10th day in healthy volunteers. In the present study serum levels of IL-2; IL-4; IL-6; IL-10, TNF-alpha, IFN- gamma, and IP-10 were evaluated prior and after a single-day intake of $3-4 \mathrm{~g}$ Isoprinosine in 6 patients with chronic hepatitis $B(\mathrm{CHB})$ and in 21 healthy probands. The cytokine concentrations were measured by human cytometric bead array (CBA) Th1/Th2 cytokine kit II and CBA IP-10 Flex Set (BD Biosciences, San Jose, CA, USA). More frequently detected cytokines were IL-6, IL-10 and IP-10, while IL-2, IL-4, TNF- alpha and IFN-gamma serum levels were practically undetectable. 5 out of the 6 patients $(83 \%)$ showed detectable IL- 6 serum level in all measurements, as did 9 out of the 21 controls (43\%), while IL-10 was detectable in all measurements in $5 / 6$ (83\%) of the patients and $4 / 21(19 \%)$ of the controls. Median serum concentration of IL-10 tends to increase in both groups after Isoprinosine intake, while IL-6 median level tends to increase only in the patients. Changes of IL- 6 and IL-10 were not significant. All patients (100\%) and $19 / 21(90 \%)$ of the controls had detectable IP-10 level in all measurements. Paired t-test showed a significant decrease of IP-10 in the afternoon postdosing compared to baseline values $(t=2.52 ; p<0.02)$. The difference was lost between baseline and morning levels on the following day post-dosing $(t=0.46 ; p=0.64)$. All studied cytokines were detectable in all measurements in only one healthy proband and demonstrated the
\end{abstract}


immunomodulator-dependent dynamics with increased levels of IL-2, IL-4, IL-6, IL-10, TNFalpha and IFN-gamma after Isoprinosine intake.

Keywords: inosine pranobex, rapid Isoprinosine response, healthy probands, HBV, IP-10, serum cytokine levels

\section{Introduction}

Isoprinosine is a synthetic purine derivative with immunomodulatory and antiviral properties. Beneficial results have been reported from clinical trials testing the effects of Isoprinosine in a variety of diseases including mucocutaneous Herpes simplex virus (HSV) infections, subacute sclerosing panencephalitis, genital warts, influenza, and herpes zoster infection (1). This drug is also active in subclinical Human papilloma virus (HPV) infection and should be considered an alternative treatment for this condition (2). Antiviral and immunomodulating activities of Isoprinosine were recently demonstrated in children with cellular immunodeficiency as a prophylaxis of recurrent viral infections (3). Previous studies discussed also its possible role in the treatment of chronic hepatitis $B$ and $C(1,4-6)$, including the prevention of hepatic flare after discontinuation of lamivudine (7).

Isoprinosine stimulates T-lymphocyte differentiation into T-cytotoxic cells and T-helper cells and potentiates lymphoproliferation both in vitro and in vivo (8). In addition, it enhances monocyte phagocytosis (9) and B-cell activity (10).

Isoprinosine potentiates IL-2, IL-12 and IFN-gamma production and decreases IL-3 and IL-4 production in vivo (11-13). In a previous study with healthy volunteers we observed

an increased serum level of IFN-gamma, IL-2, IL-10, and TNF-alpha on the 7th through to the 10th day during Isoprinosine intake (14). Furthermore, we recently described a rapid Isoprinosine response in healthy probands after single-day Isoprinosine intake. However, there are no data regarding the rapid effect of Isoprinosine on cytokine production both in patients with chronic hepatitis B and in healthy adults (15).

\section{Aim}

The aim of the present study was to evaluate the rapid cytokine production after one-day administration of Isoprinosine in patients with chronic hepatitis B, compared to healthy subjects.

\section{Materials and methods}

Twenty-seven participants were studied -6 patients with chronic hepatitis $B$, not receiving interferon, and 21 healthy adults, without current complaints, not receiving medications known to influence the study parameters. Participants were instructed not to change their routine diet, exercise, or lifestyle while participating in the study. 
The study was approved by the Institutional Ethics Committee, and all participants signed an informed consent prior to recruitment.

Five venepunctures were performed for each healthy proband. Three of them were prior to Isoprinosine intake at 8:00 a.m. and at 5:00 p.m. on Day-1, as well as at 8:00 a.m. on Day-2. The remaining two venepunctures were done after dosing at 5:00 p.m. on Day-2 and at 8:00 a.m. on Day 3 (Figure 1).

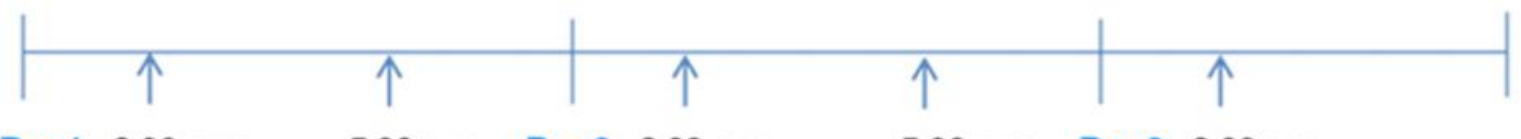

Day1 8.00 a.m. 5.00 p.m. Day2 8.00 a.m. $\quad 5.00$ p.m. Day3 8.00 a.m.

\section{Isoprinosine intake $50 \mathrm{mg} / \mathrm{kg}$}

\section{Figure 1. Study schedule}

Three blood samples were collected from patients with chronic hepatitis $B$ : at 5:00 p.m. on the day before dosing; at 08:00 a.m. (prior to dosing) and at 05:00 p.m. after dosing with Isoprinosine.

Each participant was assigned to receive Isoprinosine (Newport Pharmaceuticals Ltd., tabl. $500 \mathrm{mg}) 50$ $\mathrm{mg} / \mathrm{kg}$ b.w. 3 or 4 times daily for 1 single day - starting at Day 2, after the venepuncture at 8:00 a.m. The intake was limited to every 2 hours after the venepuncture - at 8:00 a.m., 10:00 a.m., 12:00 a.m. and 2:00 p.m. The morning blood samples at 08:00 a.m. were drawn after an overnight fast.

All venepunctures were performed by a single nurse in the same order to assure equal intervals in every recruited participant. The serum samples were anonymized and stored at $-70 \mathrm{oC}$. The concentrations of the following cytokines were further measured IL-2, IL-4, IL-6, IL-10, TNF-alpha, IFN-gamma and IP-10 by means of human cytometric bead array (CBA) Th1/Th2 cytokine kit II and CBA IP-10 Flex Set (BD Biosciences, San Jose, CA, USA). The theoretical detection limits of these kits were $2.6 \mathrm{pg} / \mathrm{ml}$ for IL-2, 2.6 $\mathrm{pg} / \mathrm{ml}$ for IL-4, 3.0 pg/ml for IL-6, $2.8 \mathrm{pg} / \mathrm{ml}$ for IL-10, $2.8 \mathrm{pg} / \mathrm{ml}$ for TNF-alpha, $7.1 \mathrm{pg} / \mathrm{ml}$ for IFN-gamma and $0.5 \mathrm{pg} / \mathrm{ml}$ for IP-10. The maximum detection limits of all kits were $2,500 \mathrm{pg} / \mathrm{ml}$. Data were acquired on a FACSCanto II flow cytometer, using FACSDiva v.6.2.1. and FCAP Array Software for analysis, all from BD Biosciences, San Jose, CA, USA.

Nonparametric Mann-Whitney U-test and paired t-tests were used to assess differences at each baseline and follow up interval.

\section{Results}

More frequently detected cytokines were IL-6, IL-10 and IP-10, while IL-2, IL-4, TNF-alpha and IFNgamma serum levels were practically undetectable.

\section{IL-6 levels}


Five of the 6 patients (83\%) and 9 of the 21 controls (43\%) displayed detectable IL-6 serum level in all mesurements. Alterations of the IL- 6 levels in both groups are presented on figure 2 .

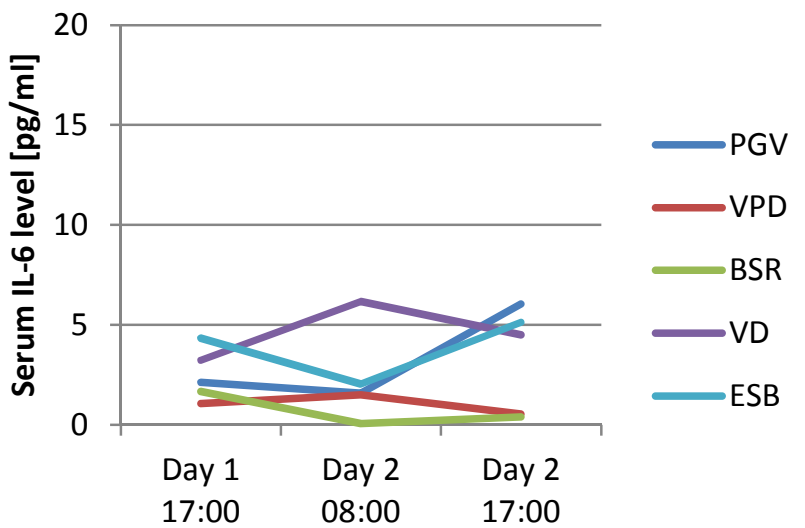

a

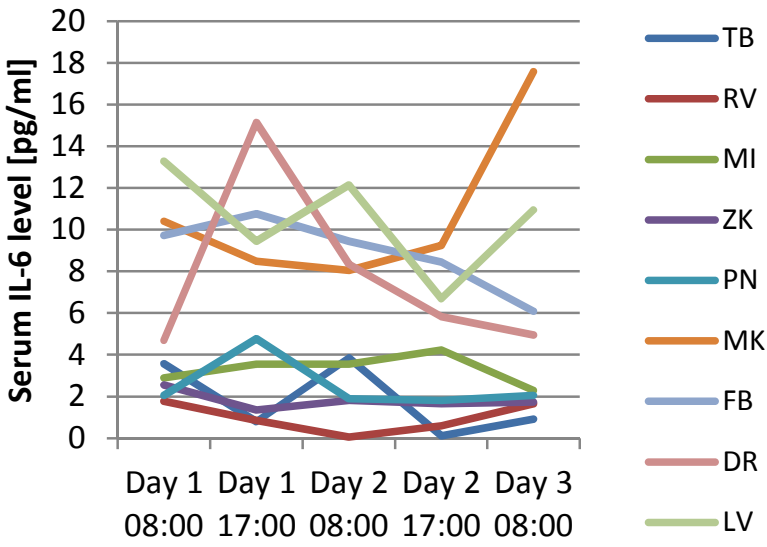

b

Figure 2. Alterations of the IL-6 levels in: a) patients with chronic hepatitis B and b) controls

In the morning prior to Isoprinosine intake the median IL-6 level was lower in CHB patients versus controls, but this difference was not significant: $1.58(0.07-6.16) \mathrm{pg} / \mathrm{ml}$ versus $3.85(0.06-12.14) \mathrm{pg} / \mathrm{ml}$; $p>0.05$. In CHB patients the median IL-6 level tends to increase 9 hours after the first Isoprinosine dose, although changes in both groups were not significant $(p>0.05)$ - figure 3 .

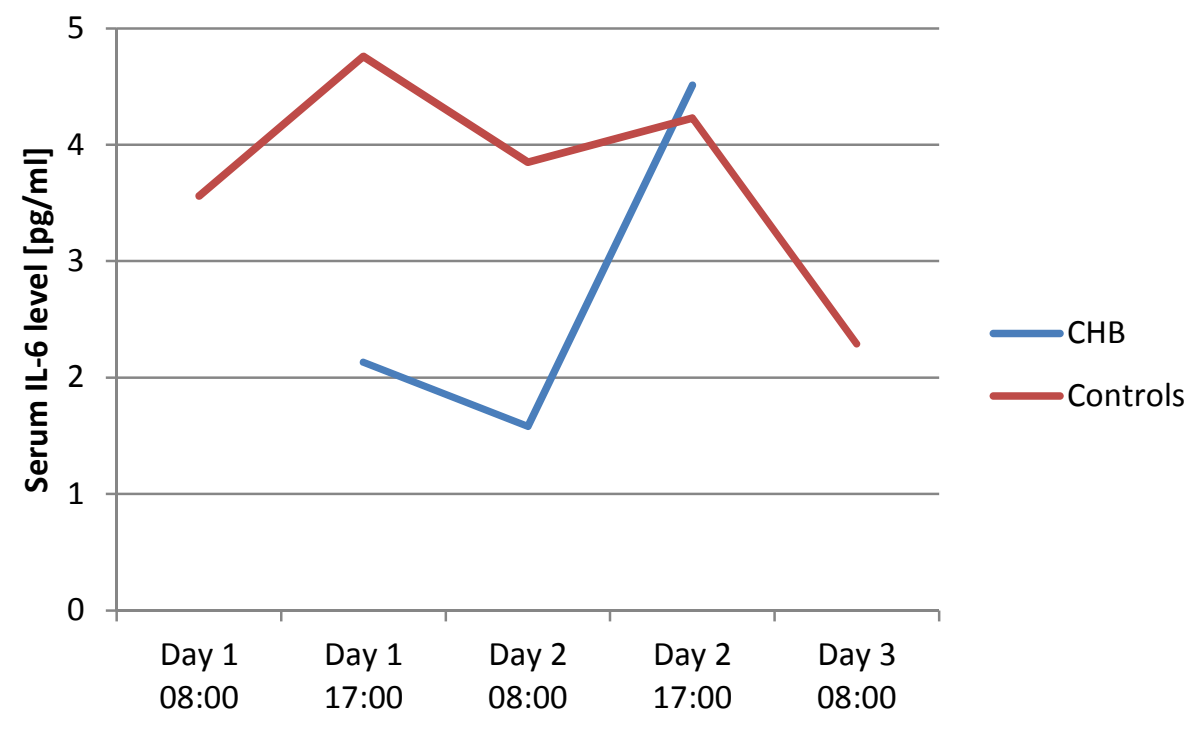

Figure 3. Median IL-6 level in CHB patients and controls

\section{IL-10}


$5 / 6(83 \%)$ patients and 4/21 (19\%) controls were with detectable IL-10 serum levels at all measurements. Alterations of IL-10 level in both groups are presented on figure 4 .

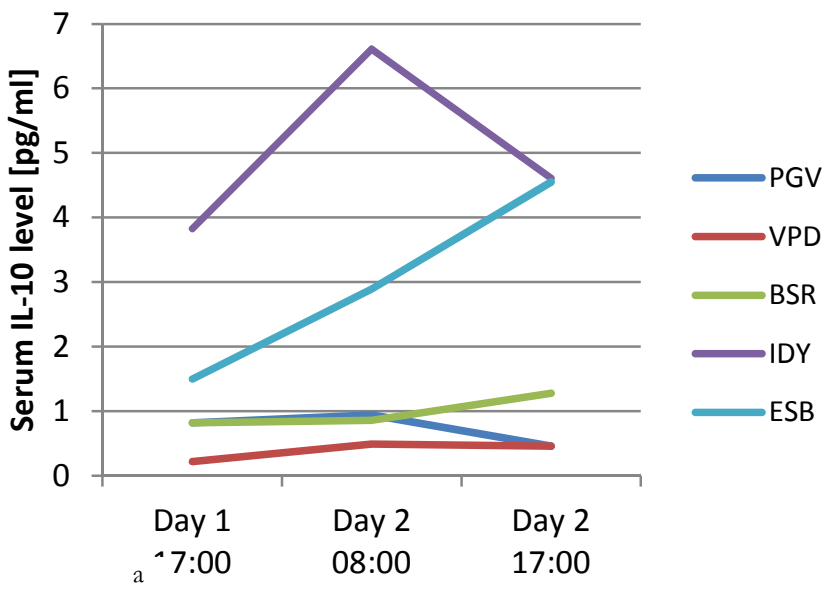

a

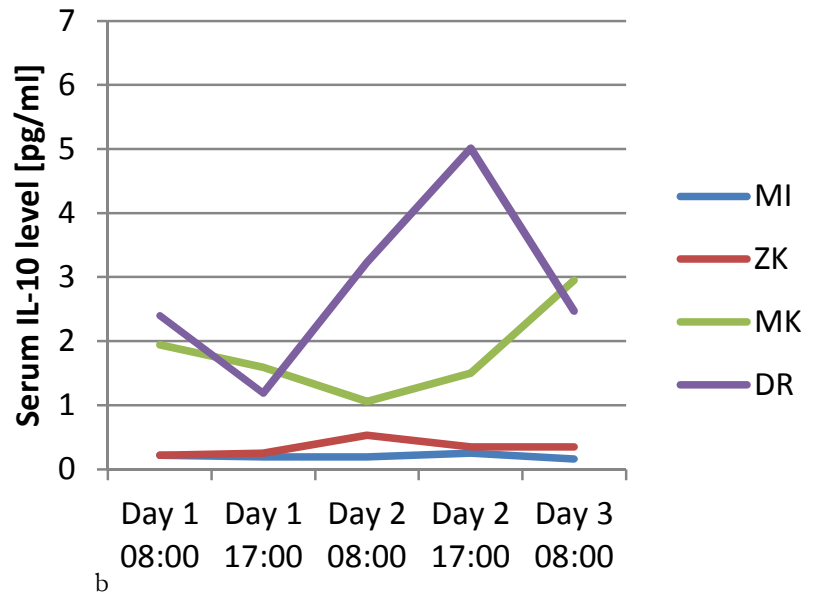

b

Figure 4. Alterations of the IL-10 levels in: a) CHB patients and b) controls

The median baseline of IL-10 level prior to Isoprinosine intake was similar in patients and controls: 0.94 $(0.49-6.61) \mathrm{pg} / \mathrm{ml}$ and $0.80(0.19-3.23) \mathrm{pg} / \mathrm{ml} ; \mathrm{p}>0.05$, respectively. It tends to increase in both groups, although not reaching significance $(p>0.05)$ - figure 5

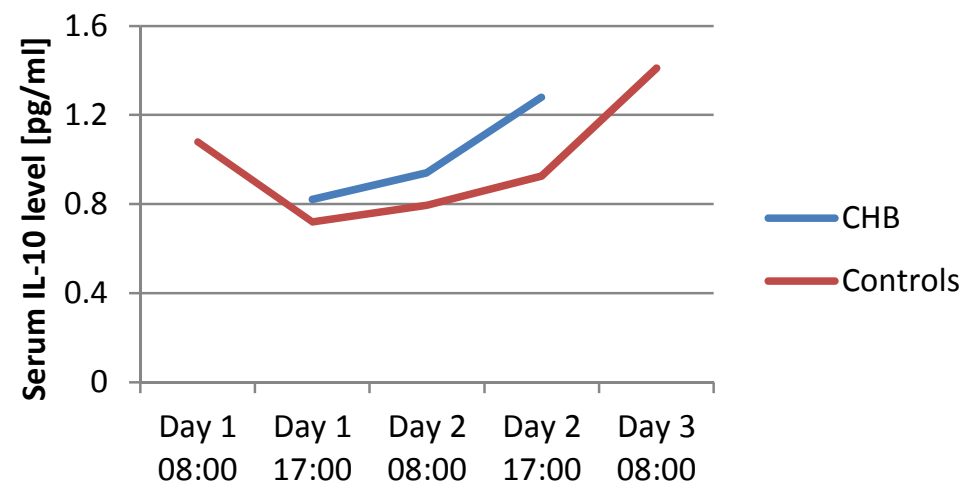

Figure 5. Median IL-10 levels in CHB patients and controls

IP-10

The most remarkable alterations were recorded for IP-10 serum level. All patients (100\%) and 19/21 $(90 \%)$ of controls had detectable serum IP-10 level at all measurements - figure 6. 


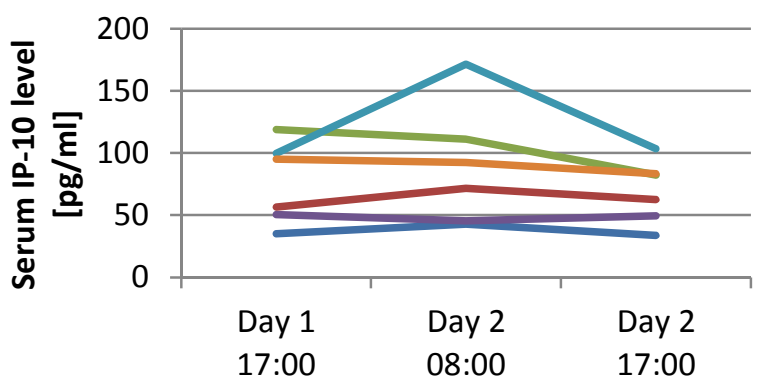

a

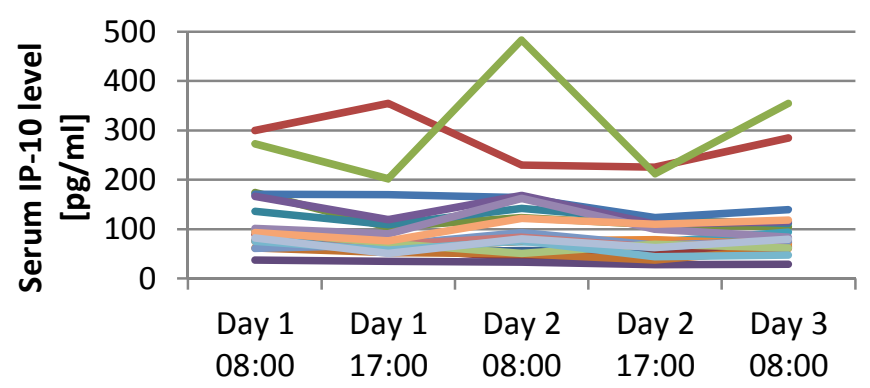

b

Patients and controls were with similar median IP-10 levels prior to Isoprinosine intake:

$82(43-171) \mathrm{pg} / \mathrm{ml}$ and 74 (33 - 482) pg/ml; p > 0.05, respectively. The median IP-10 levels remained similar in patients and controls in the afternoon on Day-2 (post Isoprinosine intake): 72 (34-103) $\mathrm{pg} / \mathrm{ml}$ versus 80 (28-226) $\mathrm{pg} / \mathrm{ml}$; $\mathrm{p}>0.05$, respectively. However, in the whole group of patients pluscontrols paired t-test showed a significant decrease of IP-10 level at 17:00 o'clock on day-2 compared to values at 08:00 o'clock on the same day $(t=2.52 ; p<0.02)$. Similarly in the controls paired t-test indicated a significant decrease of IP-10 levels between 08:00 and 17:00 o'clock on day-2 $(\mathrm{t}=2.12$; $p<0.05)$, but it was lost between levels at 08:00 o'clock on day-2 and on day-3 $(t=0.46 ; p=0.64)$. The paired t-test failed to confirm significant decrease of IP-10 levesI after Isoprinosine intake in CHB patients due to the small patient group, but the expression of IP-10 levels as a percentage of its value at 08:00 o'clock on day-2 (marked as 100\%) showed median decrease of IP-10 with almost $12 \%$. A decrease in the mean value of about $25 \%$ was also confirmed in the control group - figure 7 .

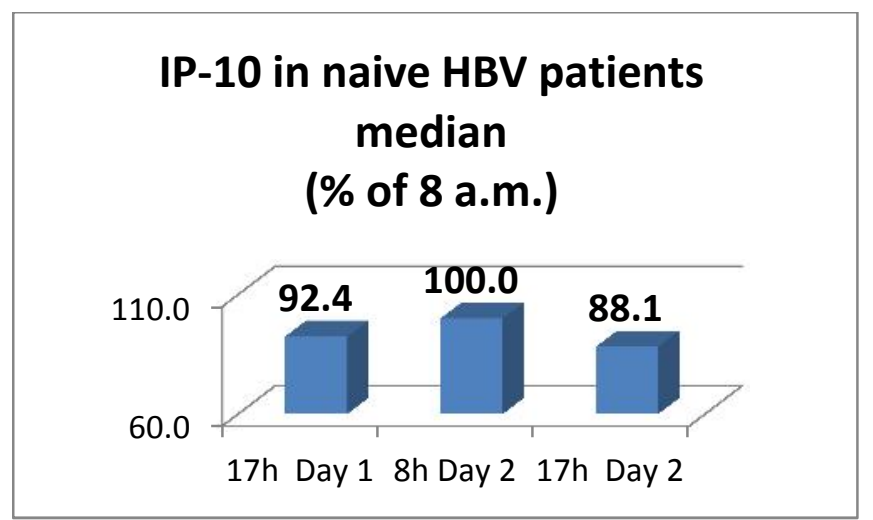

a

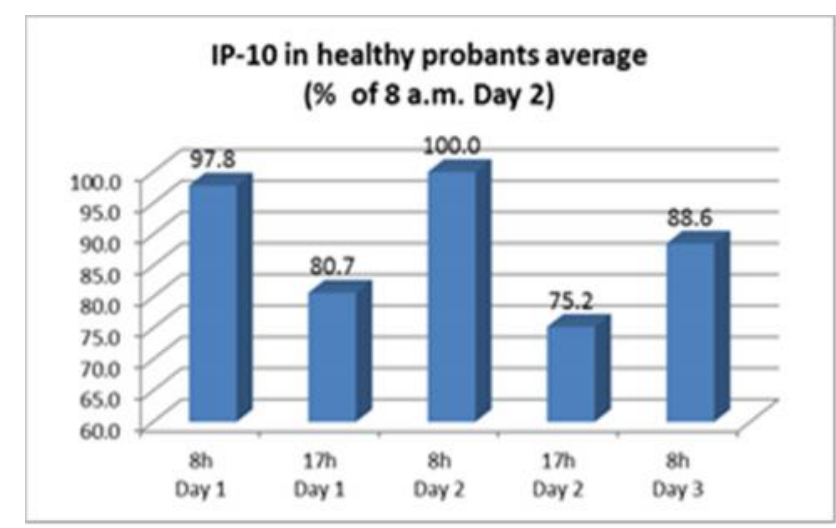

b

Figure 7. Percentage of IP-10 decrease from the level at 08:00 o'clock on Day-2 in: a) CHB patients and b) controls

All patients and $17 / 19$ of controls were with IP-10 levels below $200 \mathrm{pg} / \mathrm{ml}$ and in all of them the IP-10 levels remained $<200 \mathrm{pg} / \mathrm{ml}$ after Isoprinosine intake. Only 2 controls were with IP-10 $>200 \mathrm{pg} / \mathrm{ml}$. After Isoprinosine intake, the IP-10 level in one of them decreased from 482 to $212 \mathrm{pg} / \mathrm{ml}$ with further increase to $354 \mathrm{pg} / \mathrm{ml}$ on the next day without Isoprinosine - figure $6 \mathrm{~b}$. In the other proband the IP-10 level remained relatively unchanged after Isoprinosine intake and fluctuated above $200 \mathrm{pg} / \mathrm{ml}$. 


\section{Individual data}

All studied cytokines were detectable in any measurement in one subject. The observed alterations of IL2, IL-4, IL-6, IL-10, TNF-alpha, IP-10 and IFN-gamma are presented on figure 8.

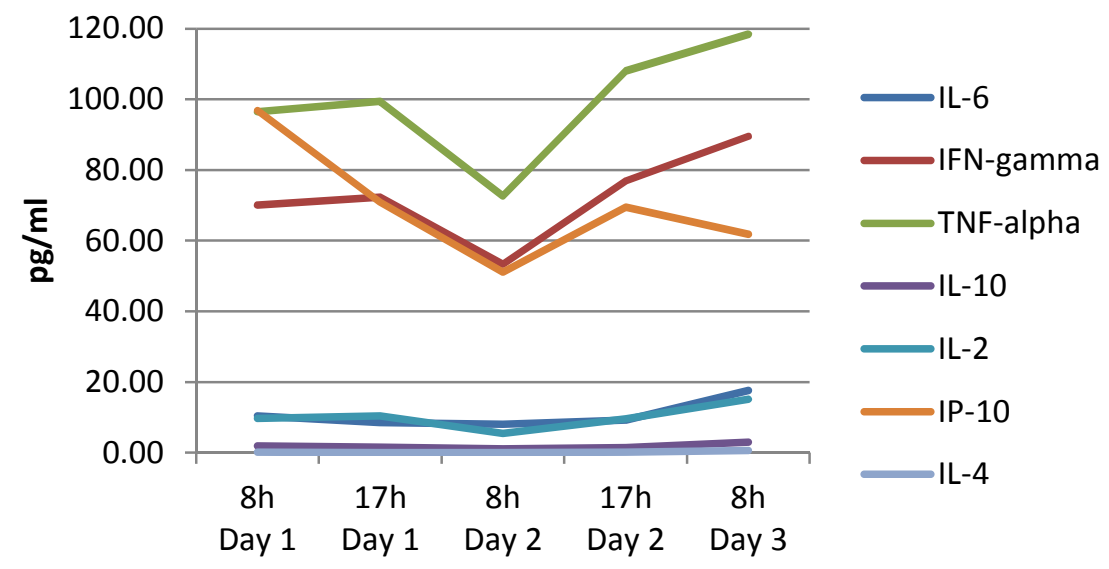

Figure 8. Cytokine levels in a single subject from the control group - alterations prior to, during and after Isoprinosine intake

Six subjects (2 CHB patients and 4 controls) were with detectable IL-6, IL-10 and IP-10 levels in almost all measurements. $2 / 6$ and $5 / 6$ of them displayed increased IL-6 and IL-10 levels after Isoprinosine intake. IP10 decreased in 4 subjects, remained relatively unchanged in 1 and slightly increased in 1 subject figure 9 .

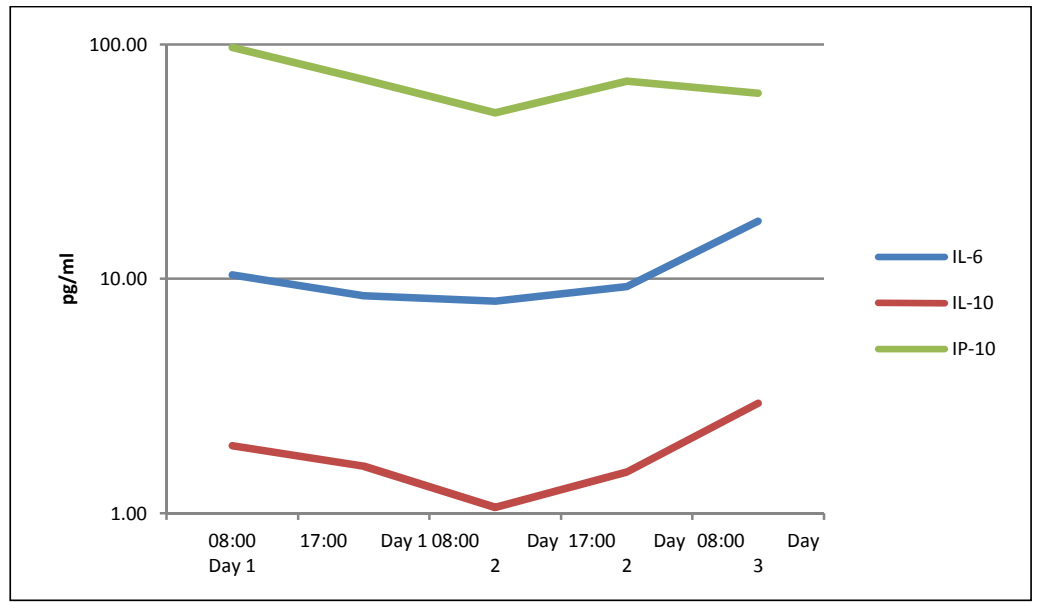



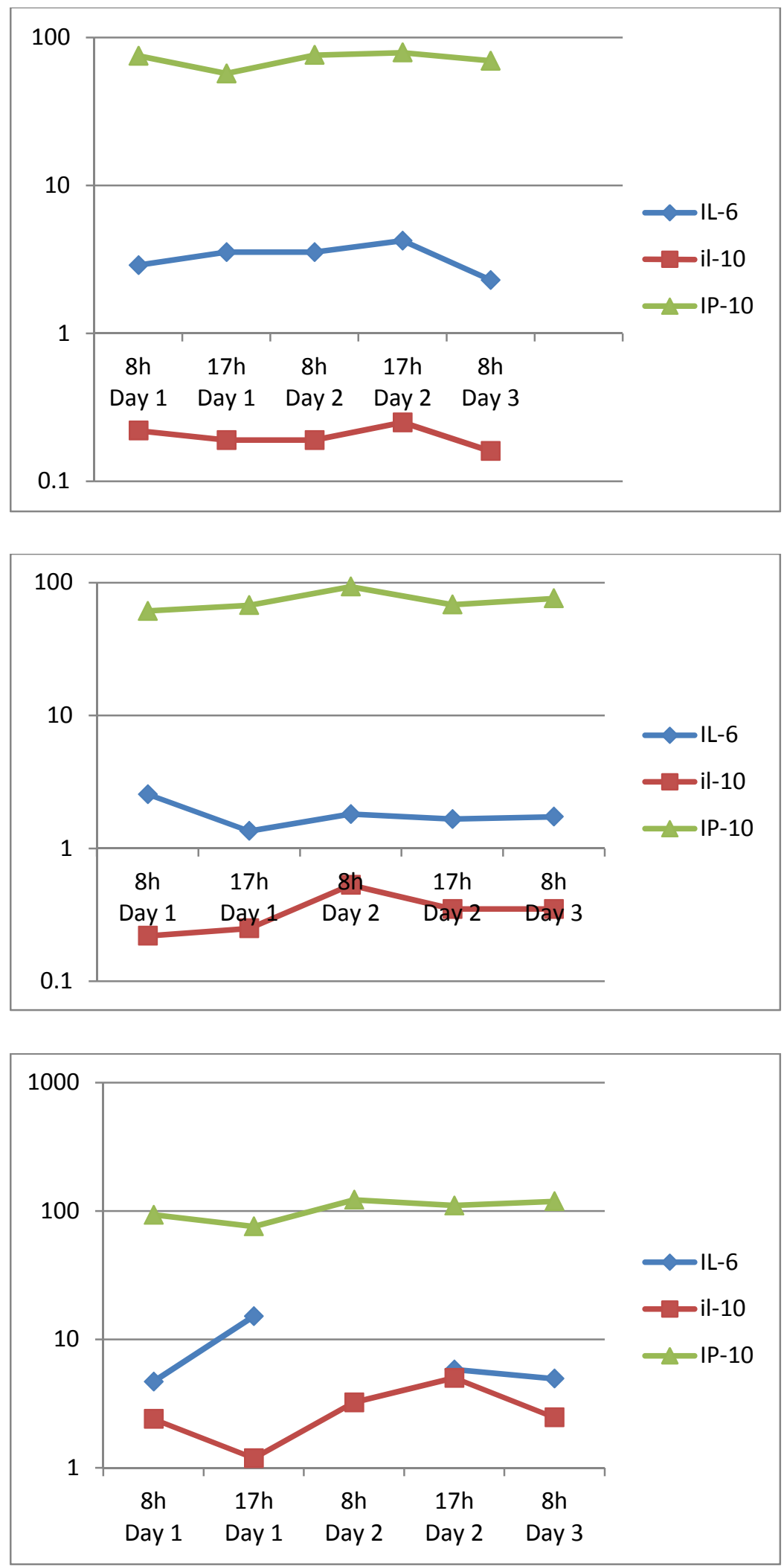

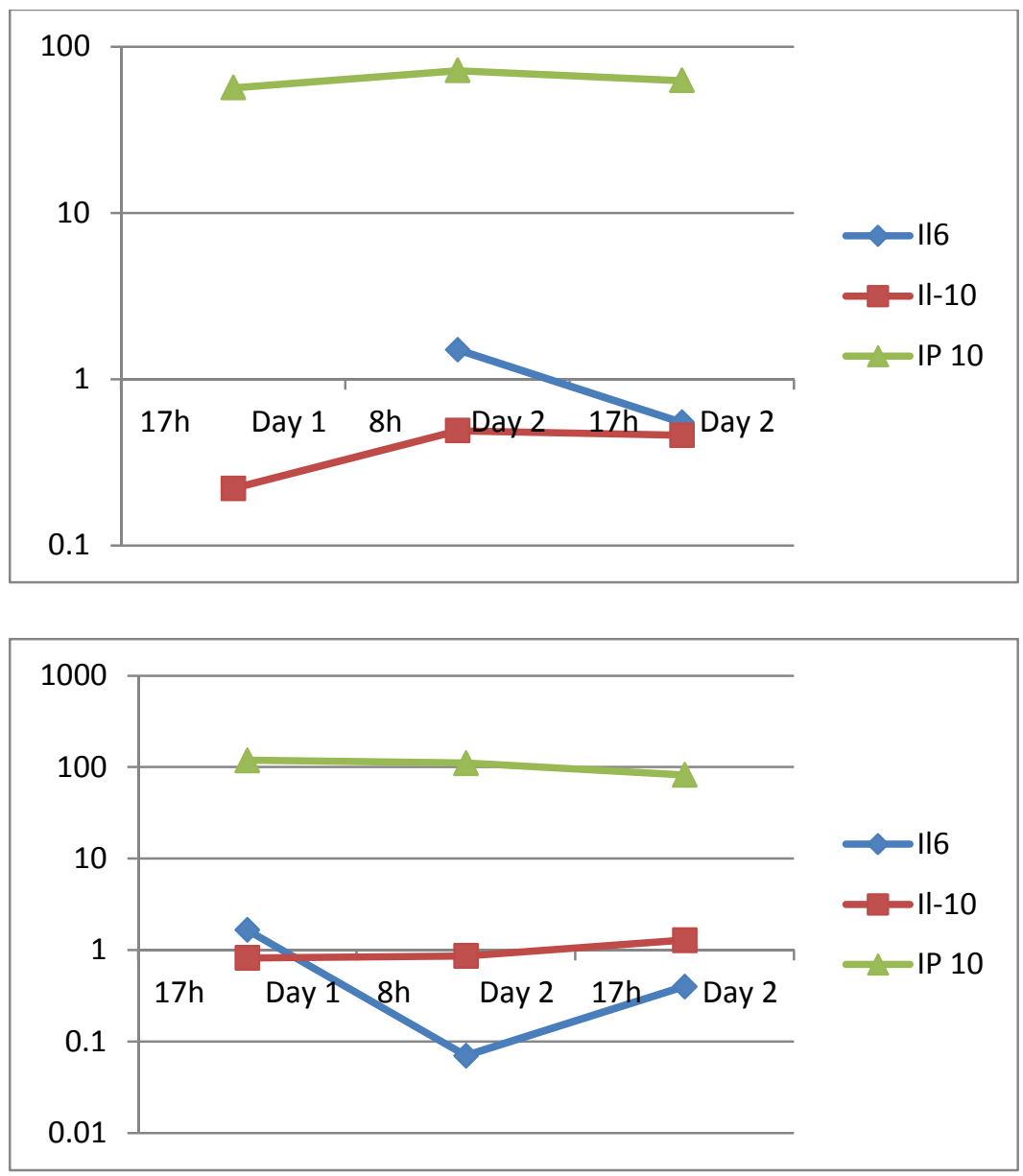

Figure 9. Alterations of IL-6, IL-10 and IP-10 levels in 6 individual subjects

\section{Discussion}

Isoprinosine is a synthetic drug, which consists of inosine and p-acetamidobenzoate salt of N,Ndimethylamino-2-propanol (1). It is an immunomodulating agent that potentiates both T-lymphocyte and phagocytic cell function $(9,16)$. It induces the appearance of phenotypic markers of differentiation on immature precursor T cells; augments helper or suppressor T-cell functions, and increases the production of TNF- $\beta$ (17). Isoprinosine can also enhance IL-2 production, upregulating the expression of the IL-2 receptor in vitro (18). Treatment of human PBMC with Isoprinosine enhances IL-2 production by PBMC (1). We have found that Isoprinosine increases the serum concentration of IL-2, IL-10 and IFN-gamma in healthy adults (14).

In the present study we evaluated the kinetics of various cytokines prior to and after single-day Isoprinosine intake both in healthy subjects and in CHB patients. IP-10 was the most frequently detected cytokine in both groups. We found a significant decrease of IP-10 levels in the afternoon after Isoprinosine intake which disappeared on the next

day. 
It should be noted that IL-2, IL-4, TNF-alpha and IFN-gamma were practically undetectable. All studied cytokines were detectable in any measurement in only one healthy proband and the observed alterations clearly demonstrated the immunomodulator-dependent dynamics with increased levels of IL-2, IL-4, IL-6, IL-10, TNF-alpha and IFN-gamma after Isoprinosine intake - figure 8.

IL-10 and IL-6 levels were detected only in a small proportion of healthy subjects, while the majority of $\mathrm{CHB}$ patients were with detectable serum levels of both cytokines. The observed changes of IL-6 and IL10 serum levels have not reached statistical significance. Nevertheless, the median serum concentration of IL-10 tends to increase in both groups after Isoprinosine intake. In healthy probands median the IL-6 level remained relatively unchanged on the day of Isoprinosine intake and tends to decrease thereafter. In contrast, median production of IL-6 in CHB patients tends to increase after Isoprinosine intake.

The observed pattern of cytokine changes in both groups is probably related to recently-described rapid immune response after one-day Isoprinosine intake (15). In a previous study we have evaluated the absolute number of large lymphocytes and monocytes prior to and after Isoprinosine intake in the same group of healthy probands (15). The blood samples were also collected the same time points (15). A significant increase of presumably activated cells was found in $76 \%$ of healthy adults after intake of $3-4 \mathrm{~g}$ of Isoprinosine in a single-day. About $60 \%$ of rapid responders kept this activation until the next day (15). Together all these data probably suggest that absolute number of large lymphocytes and monocytes reflects better the rapid immune response to Isoprinosine than serum cytokine levels.

\section{References}

1. Campoli-Richards DM, Sorkin EM, Heel RC. Inosine pranobex. A preliminary review of its pharmacodynamic and pharmacokinetic properties, and therapeutic efficacy. Drugs 1986; 32(5): 383-424.

2. Tay SK. Efficacy of inosine pranobex oral therapy in subclinical human papillomavirus infection of the vulva: a randomized double-blinded placebo controlled study. Int. J. STD. AIDS. 1996; 7(4): 276-280.

3. Gołebiowska-Wawrzyniak M, Markiewicz K, Kozar A et al. Immunological and clinical study on therapeutic efficacy of inosine pranobex. Pol. Merkur. Lekarski. 2005;19(111): 379-382.

4. De Luca D, Russo V, Caporale G, et al. A. Study of the cell-mediated immunity in asymptomatic carriers of viral hepatitis (HBsAg) surface antigens and hypothesis on the elimination of these antigens with isoprinosine. Arch Med Genral. 1980; 32: 635-640.

5. Cianciara J, Laskus T, Gabinska E, Loch T. Isoprinosine in the treatment of chronic active hepatitis B. Scand J Infect Dis. 1990; 22: 645-648.

6. Nikolova N, Antonov K, Mateva L, Krastev Z. Could Inosine pranobex and Ribavirin in combination restore immune competence in chronic HCV advanced liver disease? Medlnform. 2014; 1 : 35-44. 
7. Krastev Z, Antonov K, Jelev D. The prevention of an expected hepatic flare in HBe negative patients after lamivudine discontinuation. J Gastrointestin Liver Dis. 2006;15 (4): 389-91.

8. Hadden JW. T-cell adjuvants. Int J Immunopharmacol. 1994; 16(9):703-710.

9. Wybran J, Govaerts A, Appleboom T. Inosiplex a stimulating agent for normal human T cells and human leukocytes. J Immunol. 1978; 121:1184-1187.

10. Morin A, Tournaine JL, Renoux G, Hadden J. Isoprinosine as an immunomodulating agent. In: New Trends in Human Immunology and Cancer Immunotherapy (eds Serrou B and Rosenfeld C), Doin-Saunders, Paris 1980,1021 - 1032.

11. Lomnitzer R. Isoprinosine potentiation of human peripheral blood mononuclear cell response to mitogens: kinetics and effect on expression of the IL-2 receptor and the activity of interleukin 2 . J Clin Lab Immunol. 1988; 27(2): 91-96.

12. Cillari E, Dieli M, Lo Campo P, Sireci G, Caffarelli A, Maltese E, Millott S, Milano S, Liew FY. Protective effect of Isoprinosine in genetically susceptible BALB/c mice infected with Leishmania major. Immunology. 1991; 74(1): 25-30.

13. Milano S, Dieli M, Millott S, Miceli MD, Maltese E, Cillari E. Effect of isoprinosine on IL-2, IFNgamma and IL-4 production in vivo and in vitro. Int J Immunopharmacol. 1991; 13(7): 1013-1018.

14. Petrova $M$, Jelev D, Ivanova A, Krastev Z. Isoprinosine affects serum cytokine levels in healthy adults. J. Interferon Cytokine Res. 2010; 30(4): 223-228.

15. Krastev Z, Jelev D, Ivanova R. Isoprinosine induces a rapid lympho-mononuclear response in adult probands. Medlnform. 2015; 1: 80-85.

16. Wybran J, Faman JP, Gortz R. Inosiplex (Isoprinosine): a review of its immunological and clinical effects in disease. Adv Pharmacol Ther. 1982; 6:123-131.

17. Morin A, Ballet JJ. A recent review on in vitro and in vivo immunological activities of methisoprinol. Allergol Immunopathol (Madrid). 1982; 10:109-114.

18. Tsang KY, Boutin B, Pathak SK et al. Effect of isoprinosine on sialylation of interleukin-2. 1986; Immunol. Lett. 12(4), 195-200.

\section{Corresponding author}

Deian Jelev

Clinic of Gastroenterology,

University Hospital "St. Ivan Rilski",

15, Acad Ivan Geshov Blvd.

Sofia 1431

Bulgaria

Phone: +3592952 6319 
Fax: +35928510816

e-mail: detjelev@gmail.com 